\title{
Bidirectional Double Muscle Transfer to Restore Shoulder Abduction and External Rotation in Late Obstetric Brachial Plexus Injuries
}

\section{Mohammad-Reda Ahmad*}

Department of general surgery, Plastic and Reconstructive Surgery Unit, Faculty of Medicine, Zagazig University, Egypt

\begin{abstract}
Background: Internal rotation contracture is the most frequent and important secondary deformity of the shoulder in birth palsy. Many techniques have been tried to solve this problem.
\end{abstract}

Aim: To improve shoulder abduction and external rotation in obstetric brachial plexus injuries (OBPIs) by performing an ordinary Single Muscle Transfer (SMT) or Bidirectional Muscle Transfer (BMT) around the shoulder. Patients and methods: 40 patients: 21 male and 19 female their age ranged from 2 to 10 years complaining of lake of shoulder abduction and external rotation due to OBPIs. They were divided into two groups according to the performed operation: group 1 (17 patients) operated with BMT and group 2 (23 patients) operated with SMT.

Results: There was significant postoperative improvement in shoulder abduction, external rotation and flexion in both procedure "BMT and SMT". In addition, the young age gives better results as there are negative correlation between patient age and degree of shoulder functions improvement in both groups. Moreover, BMT procedure had significant higher degree of improvement in shoulder abduction and external rotation than SMT procedure.

Conclusion: Bidirectional muscle transfer is recommended as an optimal procedure to improve shoulder abduction and external rotation in late obstetric brachial plexus injuries.

Keywords: Bidirectional; Brachial plexus; Shoulder; External rotation

\section{Introduction}

Obstetric brachial plexus injuries (OBPIs) is a mixed nerve and musculoskeletal complication that happens during the process of difficult delivery [1]. A considerable percent of cases tends to acquire lifelong limb deficits [2]. The fast limb growth with marked asymmetry in the pathology of nerve involvement within the brachial plexus, may lead to a lot of sequelae as muscle contracture, weakness, and imbalances. These deformities become more evident with failure of growth of the denervated muscles, or at least developed at a lower rate than the antagonist innervated muscles. Teathering effect may develop gradually, that limits the passive range of motion around the shoulder joint. And muscle imbalances and contractures can lead to a lot of bony deformities [3]. In addition, bony deformities can also result from decreased innervation from the brachial plexus to shoulder joint bones $[4,5]$.

All the previous prerequisites can lead to progressive and persistent glenohumeral $(\mathrm{GH})$ joint dysplasia and shoulder joint sublaxation and dislocation [6].

Muscle balance between agonists and antagonists around the shoulder joint is the main aim of the treatment. This aim can be achieved firstly by release of the teathering contractures of the internal rotators. Many techniques had been published for this release, as posterior subscapularis muscle slide, or through anterior approach lengthening of the tendon of subscapularis. Through this anterior approach the tendon of pectoralis major can be also lengthen, and any ligamentous or capsular contractures can be dealt with $[7,8]$.

If the active external rotation and abduction were not recovered well, muscle transfer can be done in supple and congruent GH joint. If there is severe glenohumeral dysplasia with internal rotation contraction especially in older children, then external humeral osteotomy is preferred $[9,10]$.

In this research, the bidirectional double muscle transfer is proposed to improve shoulder functions after late OPPIs and compared with the single muscle transfer.

\section{Patients and Methods}

\section{Patient data analysis}

From January 2011 to June 2014 forty patients $\{21$ male (52.5\%) 19 female (47.5\%)\} were operated. They were divided into two groups according to the performed operation (Table 1). Ethical committee permission was granted for this study (approved by the Institutional Review Board and ethics committee of faculty of medicine- Zagazig University) and written consent of patients was also taken.

Group 1 (17 patients) operated with bidirectional double muscle transfer (BDMT): their age ranged from 2 to 10 years mean \pm SD $(4.18$ $\pm 2.24)$. Affected side was the right side in 10 cases $(58.82 \%)$ and left side in 7 (41.18\%). The affected roots were C5-6 in 1 case (5.89\%), C56-7 in 11 cases $(64.70 \%)$ and total in 5 cases $(29.41 \%)$. The follow up period: ranged from 6 to 36 months mean \pm SD $(18.76 \pm 7.35)$. Before operation, degree of shoulder abduction ranged from 30 to 75 degrees, shoulder external rotation ranged from zero to 20 and shoulder flexion ranged from 0-30.

Group 2 (23 patients) operated with Single Muscle Transfer (SDMT): their age ranged from 2 to 9 years mean \pm SD $(4.48 \pm 1.93)$. Affected side was the right side in 8 cases $(34.78 \%)$ and left side in 15 $(65.22 \%)$. The affected roots were C5-6 in 3 cases $(13.04 \%)$ and C56-7 in 20 cases (86.96\%). The follow up period: ranged from 6 to 38 months mean $\pm \mathrm{SD}(19.74 \pm 9.25)$. Before operation, degree of shoulder

*Corresponding author: Ahmad MR, MD, Department of general surgery, Plastic and Reconstructive Surgery Unit, Faculty of Medicine, Zagazig University, Egypt, Tel: 002/01001715406; E-mail: mohammadelhanafy@yahoo.com

Received December 27, 2014; Accepted February 02, 2014; Published February 10,2015

Citation: Ahmad M (2015) Bidirectional Double Muscle Transfer to Restore Shoulder Abduction and External Rotation in Late Obstetric Brachial Plexus Injuries. Surgery Curr Res 5: 216. doi:10.4172/2161-1076.1000216

Copyright: (c) 2015 Ahmad M. This is an open-access article distributed under the terms of the Creative Commons Attribution License, which permits unrestricted use, distribution, and reproduction in any medium, provided the original author and source are credited. 
Citation: Ahmad M (2015) Bidirectional Double Muscle Transfer to Restore Shoulder Abduction and External Rotation in Late Obstetric Brachial Plexus Injuries. Surgery Curr Res 5: 216. doi:10.4172/2161-1076.1000216

Page 2 of 5

\begin{tabular}{|c|c|c|c|c|c|c|c|c|c|c|c|c|c|c|c|c|c|c|}
\hline \multirow{2}{*}{$\begin{array}{l}\text { Affected } \\
\text { root }\end{array}$} & \multicolumn{3}{|c|}{$\geq 18$ month post } & \multicolumn{3}{|c|}{12 month post } & \multicolumn{3}{|c|}{6 month post } & \multicolumn{3}{|c|}{ Preoperative } & \multirow{2}{*}{$\mathrm{F} \mathrm{U} / \mathrm{M}$} & \multirow{2}{*}{ Side } & \multirow{2}{*}{$\begin{array}{l}\text { Pre. } \\
\text { Op. }\end{array}$} & \multirow{2}{*}{ Sex } & \multirow{2}{*}{ Age $(y)$} & \multirow{2}{*}{ N } \\
\hline & $\mathrm{FL}$ & ER & $A b$ & $\mathrm{FL}$ & ER & $A b$ & $\mathrm{FL}$ & ER & $A b$ & $\mathrm{FL}$ & ER & $A b$ & & & & & & \\
\hline C5-6-7 & & & & 70 & 95 & 150 & 70 & 80 & 150 & 10 & 0 & 40 & 12 & Rt & No & $\mathrm{m}$ & 2 & 1BD \\
\hline C5-6-7 & 65 & 90 & 145 & 65 & 90 & 145 & 90 & 85 & 150 & 20 & 10 & 50 & 24 & $\mathrm{Rt}$ & 1ryex & $f$ & 2 & $2 \mathrm{BD}$ \\
\hline C5-6-7 & 60 & 85 & 150 & 60 & 90 & 150 & 70 & 85 & 110 & 10 & 0 & 75 & 24 & Rt & no & $\mathrm{m}$ & 2 & $3 B D$ \\
\hline C5-6 & & & & 75 & 80 & 150 & 100 & 90 & 150 & 10 & 20 & 50 & 12 & Rt & no & $\mathrm{m}$ & 2 & $4 \mathrm{BD}$ \\
\hline Total & 40 & 60 & 160 & 40 & 60 & 160 & 90 & 90 & 160 & 0 & 20 & 50 & 18 & $\mathrm{Rt}$ & 1ry ex & $\mathrm{m}$ & 2 & $5 \mathrm{BD}$ \\
\hline Total & 65 & 85 & 150 & 60 & 75 & 90 & 75 & 90 & 150 & 0 & 0 & 30 & 18 & Rt & no & $\mathrm{m}$ & 4 & $6 B D$ \\
\hline C5-6-7 & 80 & 85 & 140 & 80 & 85 & 130 & 80 & 90 & 140 & 20 & 0 & 60 & 24 & $\mathrm{Lt}$ & No & $\mathrm{m}$ & 3 & 7BD \\
\hline C5-6-7 & 65 & 90 & 140 & 65 & 90 & 140 & 80 & 85 & 140 & 10 & 0 & 40 & 36 & $\mathrm{Lt}$ & no & $f$ & 3 & 8BD \\
\hline Total & 65 & 65 & 120 & 65 & 65 & 120 & 75 & 70 & 120 & 10 & 0 & 50 & 30 & $\mathrm{Lt}$ & no & $\mathrm{m}$ & 4 & 9BD \\
\hline Total & & & & 50 & 55 & 110 & 75 & 75 & 120 & 0 & 20 & 50 & 12 & $\mathrm{Lt}$ & no & $\mathrm{m}$ & 4 & 10BD \\
\hline Total & 55 & 55 & 100 & 55 & 55 & 100 & 80 & 85 & 120 & 10 & 0 & 40 & 22 & $\mathrm{Rt}$ & No & $\mathrm{m}$ & 6 & $11 \mathrm{BD}$ \\
\hline C5-6-7 & & & & 60 & 55 & 95 & 90 & 90 & 140 & 30 & 10 & 60 & 17 & $\mathrm{Rt}$ & no & $f$ & 8 & $12 \mathrm{BD}$ \\
\hline C5-6-7 & & & & & & & 80 & 85 & 130 & 10 & 0 & 50 & 6 & $\mathrm{Lt}$ & No & $f$ & 4 & $13 B D$ \\
\hline C5-6-7 & & & & 60 & 65 & 100 & 70 & 80 & 120 & 10 & 20 & 60 & 16 & $\mathrm{Lt}$ & no & $f$ & 5 & 14BD \\
\hline C5-6-7 & & & & 60 & 60 & 100 & 60 & 70 & 100 & 10 & 0 & 60 & 13 & $\mathrm{Rt}$ & no & $f$ & 5 & $15 \mathrm{BD}$ \\
\hline C5-6-7 & 55 & 65 & 100 & 55 & 70 & 100 & 55 & 70 & 100 & 10 & 0 & 70 & 18 & $\mathrm{Lt}$ & No & $f$ & 5 & 16BD \\
\hline C5-6-7 & & & & 50 & 65 & 90 & 50 & 65 & 95 & 10 & 0 & 45 & 17 & $\mathrm{Rt}$ & No & $M$ & 10 & 17BD \\
\hline C5-6-7 & & & & 65 & 90 & 160 & 60 & 80 & 120 & 10 & 0 & 60 & 12 & $\mathrm{Lt}$ & no & $\mathrm{m}$ & 2 & $1 \mathrm{~S}$ \\
\hline C5-6-7 & & & & 70 & 90 & 140 & 70 & 80 & 110 & 10 & 20 & 70 & 14 & $\mathrm{Lt}$ & no & $f$ & 2 & $2 S$ \\
\hline C5-6-7 & 70 & 90 & 145 & 70 & 90 & 150 & 80 & 75 & 100 & 10 & 0 & 50 & 38 & $\mathrm{Lt}$ & no & $f$ & 2.5 & $3 S$ \\
\hline C5-6-7 & & & & 70 & 85 & 150 & 90 & 90 & 100 & 20 & 0 & 40 & 12 & $\mathrm{Lt}$ & no & $f$ & 2.5 & $4 S$ \\
\hline C5-6-7 & 60 & 85 & 140 & 60 & 85 & 140 & 70 & 85 & 110 & 10 & 0 & 60 & 6 & $\mathrm{Lt}$ & 1ry ex & $f$ & 3 & $5 S$ \\
\hline C5-6-7 & 60 & 65 & 120 & 60 & 70 & 120 & 60 & 75 & 90 & 10 & 20 & 60 & 36 & $\mathrm{Rt}$ & no & $\mathrm{m}$ & 2 & $6 S$ \\
\hline C5-6-7 & 70 & 90 & 145 & 70 & 90 & 145 & 80 & 90 & 120 & 25 & 20 & 90 & 18 & $\mathrm{Rt}$ & no & $\mathrm{m}$ & 3 & $7 S$ \\
\hline C5-6-7 & & & & 65 & 80 & 125 & 65 & 75 & 90 & 10 & 0 & 60 & 16 & $\mathrm{Lt}$ & no & $\mathrm{m}$ & 4 & $8 S$ \\
\hline C5-6-7 & 60 & 80 & 130 & 60 & 80 & 130 & 75 & 80 & 100 & 10 & 10 & 40 & 24 & $\mathrm{Lt}$ & no & $\mathrm{m}$ & 6 & $9 \mathrm{~S}$ \\
\hline C5-6-7 & 60 & 80 & 125 & 60 & 80 & 125 & 80 & 80 & 120 & 10 & 20 & 70 & 28 & $\mathrm{Lt}$ & no & $f$ & 4 & $10 \mathrm{~S}$ \\
\hline C5-6-7 & & & & 60 & 70 & 120 & 70 & 80 & 120 & 10 & 0 & 60 & 11 & $\mathrm{Rt}$ & No & $f$ & 4 & $11 \mathrm{~S}$ \\
\hline C5-6-7 & 56 & 75 & 120 & 65 & 75 & 120 & 80 & 85 & 130 & 10 & 0 & 70 & 20 & $\mathrm{Lt}$ & No & $\mathrm{m}$ & 4 & $12 S$ \\
\hline C5-6-7 & & & & 60 & 70 & 130 & 75 & 80 & 125 & 10 & 30 & 80 & 14 & $\mathrm{Lt}$ & no & $\mathrm{m}$ & 4 & $13 \mathrm{~S}$ \\
\hline C5-6-7 & & & & 60 & 65 & 120 & 65 & 65 & 120 & 10 & 0 & 80 & 10 & $\mathrm{Lt}$ & no & $f$ & 4.5 & $14 \mathrm{~S}$ \\
\hline C5-6-7 & 70 & 70 & 110 & 70 & 70 & 110 & 65 & 65 & 110 & 20 & 0 & 60 & 22 & $\mathrm{Rt}$ & No & $f$ & 9 & $15 \mathrm{~S}$ \\
\hline C5-6-7 & 65 & 70 & 110 & 65 & 70 & 110 & 60 & 70 & 110 & 20 & 0 & 50 & 36 & $\mathrm{Rt}$ & No & $f$ & 5 & $16 \mathrm{~S}$ \\
\hline C5-6 & 60 & 60 & 115 & 60 & 60 & 110 & 60 & 60 & 115 & 20 & 0 & 60 & 36 & $\mathrm{Rt}$ & No & $\mathrm{m}$ & 8 & $17 S$ \\
\hline C5-6-7 & & & & 60 & 65 & 100 & 60 & 65 & 100 & 10 & 20 & 60 & 12 & $\mathrm{Lt}$ & no & $\mathrm{m}$ & 5 & $18 \mathrm{~S}$ \\
\hline C5-6 & 60 & 60 & 100 & 60 & 60 & 100 & 60 & 60 & 100 & 10 & 0 & 50 & 19 & $\mathrm{Rt}$ & No & $f$ & 8 & $19 S$ \\
\hline C5-6-7 & 60 & 60 & 100 & 60 & 60 & 100 & 65 & 60 & 100 & 10 & 0 & 45 & 18 & $\mathrm{Lt}$ & no & $f$ & 5 & $20 S$ \\
\hline C5-6 & 65 & 60 & 100 & 65 & 60 & 100 & 60 & 60 & 100 & 10 & 0 & 50 & 18 & $\mathrm{Lt}$ & No & $f$ & 5 & $21 S$ \\
\hline C5-6-7 & & & & 60 & 65 & 100 & 60 & 60 & 100 & 0 & 0 & 50 & 14 & $\mathrm{Rt}$ & no & $\mathrm{m}$ & 5 & $22 \mathrm{~S}$ \\
\hline C5-6-7 & 60 & 60 & 100 & 60 & 60 & 100 & 60 & 55 & 110 & 10 & 0 & 70 & 20 & $\mathrm{Lt}$ & no & $\mathrm{m}$ & 5.5 & $23 S$ \\
\hline $\mathrm{D}=$ Bidire & onal & ble & & & & $\mathrm{S}=\mathrm{s}$ & & & $/ \mathrm{M}=$ & $W-L$ & $\mathrm{~m}$ & & & Pre. & prev & ope & tion & \\
\hline $\mathrm{b}=$ shoul & abd & & & & & $E R=s$ & oulder & ernal & ation & & & & & $\mathrm{FL}=$ & Ider fle & & & \\
\hline
\end{tabular}

Table 1: Patient data of bidirectional double muscle transfer and single direction muscle transfer in late OBPIs

abduction ranged from 40 to 90 degrees, shoulder external rotation ranged from zero to 30 and shoulder flexion ranged from 10-25.

In this study, two methods of transfer around the shoulder joint were done.

\section{Operative technique of the single direction muscle transfer (SDMT)}

In this technique I used a procedure similar to that of Gilbert [11] and Ahmad [12].

Patient after being anaesthetized, was lied in lateral decubitus while the affected side being up. At the start of this surgery, assessment of the passive range of movement (PROM) around the shoulder joint is so essential. Any contractures, hypertrophy of the internal rotators is to be considered. I used posterior approach at the lateral edge of the scapula in a zigzag incision. Through this approach, posterior subscapularis muscle slide and release was achieved. Then after, the conjoint tendon was dissected from surrounding structures, and the part related to latissimus dorsi (LD) muscle in the conjoint tendon was separated from that of Terrie's major muscle (tmm). Dissection and mobilization of the LD muscle to enable successful transfer to a new insertion site was done. In all previous steps (posterior subscapularis muscle release, conjoint tendon dissection, and mobilization of the upper part of LD muscle), the pedicles of the LD muscle, and tmm, should be saved and protected. After that, detaching the tendon of LD muscle from the medial side of the humerus with great protection and care to neurovascular structures of the upper arm was done. After that, the arm adjusted in $90^{\circ}$ abduction, $90^{\circ}$ external rotation, then the posterior fibers of the deltoid was elevated to make a tunnel for new insertion of LD tendon. At this step, care must be experienced to avoid injury of the fibers of the axillary nerve. I used heavy polyprolene suture to fix the 
Citation: Ahmad M (2015) Bidirectional Double Muscle Transfer to Restore Shoulder Abduction and External Rotation in Late Obstetric Brachial Plexus Injuries. Surgery Curr Res 5: 216. doi:10.4172/2161-1076.1000216

Page 3 of 5

tendon of LD into the point at the greater tuberosity of the humerus at the site of insertion of the infraspinatous. Little sutures was taken between infraspiatous muscle and transferred LD muscle belly, to make some synergism in function and direction of pull. Closure of the wound, (while the arm was in $90^{\circ}$ abduction, $90^{\circ}$ external rotation, and the elbow at $90^{\circ}$ flexion) was achieved. In the same position, shoulder spica cast was applied for 6 weeks. After removal of the cast airplane custom made splint was applied with gradual weaning for 3 months, after that physiotherapy was scheduled.

\section{Operative technique of the bidirectional double muscle transfer (BDMT)}

In this group, I used the same position, incision, and subscapularis release of previous SDMT. After release of the part of LD muscle of the conjoint tendon from the tmm part (Figure 1A and $1 \mathrm{~B}$ ).

The tendon of tmm was fixed to the inferior surface of the head of the humerus below the site of lesser tuberosity in full abduction. Care to avoid injury of the neurovascular bundle of the upper limb is essential. After that, the tendon of the LD muscle was fixed like the previous transfer to the upper most part of the greater tuberosity of the humerus, while the arm was at $90^{\circ}$ abduction and $90^{\circ}$ external rotation. I used the same fixation position, period of cast fixation, same proid of custom made brace, and the same physiotherapy schedule like SDMT (Figure 2A and 2B).

\section{Statistical analysis}

Data were presented as mean \pm standard deviation (SD). Statistical analysis was performed using the 20 version of SPSS statistical software for windows (SPSS Inc. Chicago, IL, USA). Paired student $t$ test used in the comparison between preoperative and postoperative evaluation and unpaired student $t$ test used in the comparison between 2 groups. Person correlation used to relate patient's age and postoperative improvement. P values less than 0.05 were considered significant.

\section{Results}

Table 2 shows a comparison between shoulder abduction improvements after the two operative procedures. There was significant postoperative shoulder abduction improvement in both procedure "BDMT and SDMT" when compared with the degree of abduction before operation $(\mathrm{P}=0.000)$. In addition there is negative correlation between patient age and degree of shoulder abduction improvement in both groups ( $\mathrm{r}=-572$ and $-575, \mathrm{P}=0.016$ and 0.004 respectively). Moreover, BDMT procedure had significant higher degree of improvement in shoulder abduction than SDMT procedure $(\mathrm{P}=0.000)$ with percentage of change $149.45 \%$ in comparison to $80.48 \%$ in SDMT.

Table 3 shows a comparison between shoulder external rotation improvements after the two operative procedures. There was significant postoperative shoulder external rotation improvement in both procedure "BDMT and SDMT" when compared with the degree of external rotation before operation $(P=0.000)$. In addition there is negative correlation between patient age and degree of shoulder external rotation improvement in both groups $(\mathrm{r}=-720$ and $-578, \mathrm{P}$ $=0.001$ and 0.004 respectively). Furthermore, BDMT procedure had significant higher degree of improvement in shoulder external rotation than SDMT procedure $(\mathrm{P}=0.009)$ with percentage of change $1285.54 \%$ in comparison to $1095.89 \%$ in SDMT.

Table 4 shows a comparison between shoulder flexion improvements after the two operative procedures. There was significant postoperative shoulder flexion improvement in both procedure "BDMT and SDMT" when compared with the degree of flexion before operation $(\mathrm{P}=0.000)$.
In addition there is negative correlation between patient age and degree of shoulder flexion improvement in both groups $(\mathrm{r}=-523$ and -448 , $\mathrm{P}=0.031$ and 0.032 respectively). However, there was non-significant statistical difference between the degree of improvement in shoulder flexion in both procedures $(\mathrm{P}=0.061)$ with percentage of change $602.64 \%$ in comparison to $470.73 \%$ in SDMT.

\section{Discussion}

Progressive and lifelong deformities of the shoulder represent the most common complications of OBPIs are [13-15].

Many authors considered muscle release procedure is indicated in internal rotation contracture before the age of two years, and the muscle transfer to achieve good external rotation and abduction in older children [16].

It is logic to use the procedure of muscle release and transfer before evident dysplasia of GH joint that usually happened at age of 3 or 4 year [17].

Gilbert et al. [18] and many authors suggested that the release of the internal rotation contracture is indicated if passive external rotation is

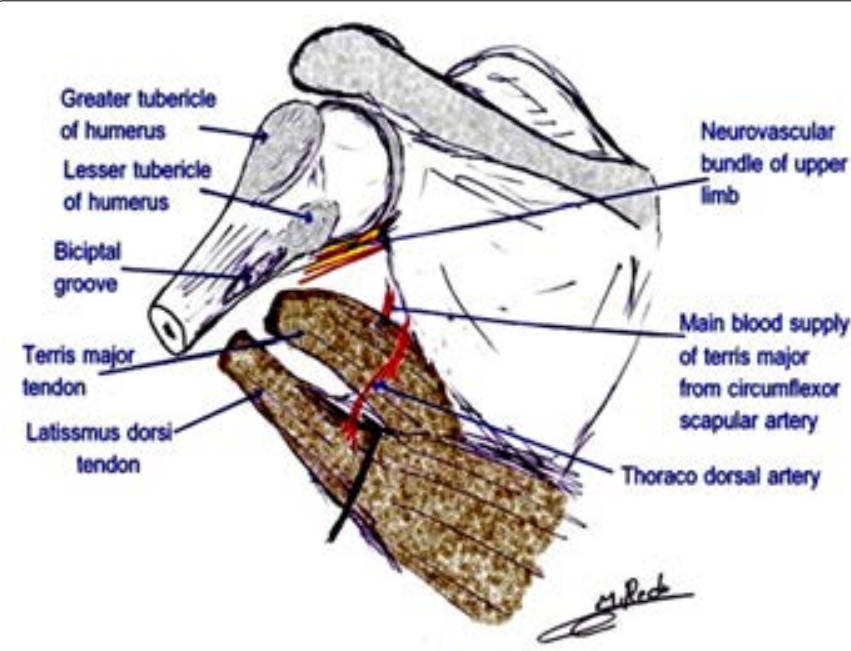

Figure 1a: Diagram for the dissection of the tendons of latissimus dorsi and terris major muscles and their pedicles.

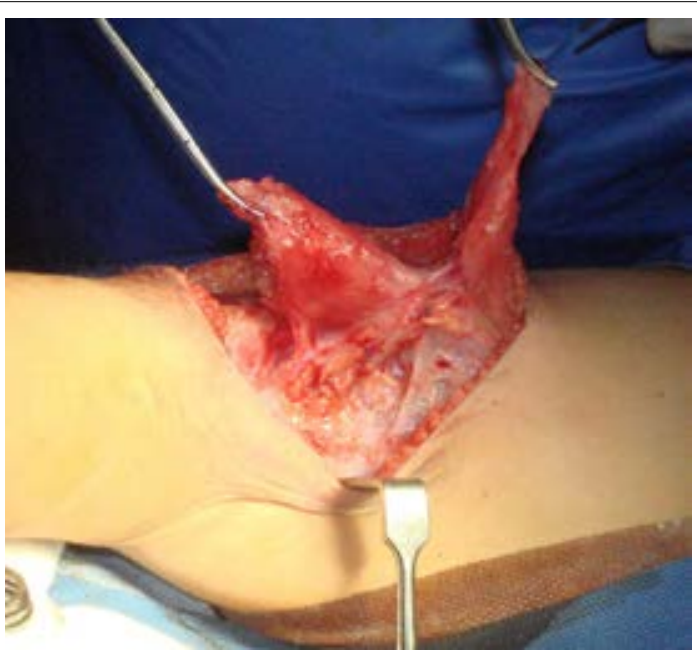

Figure 1b: The dissection of the tendons of latissimus dorsi and terris major muscles and their pedicles. 


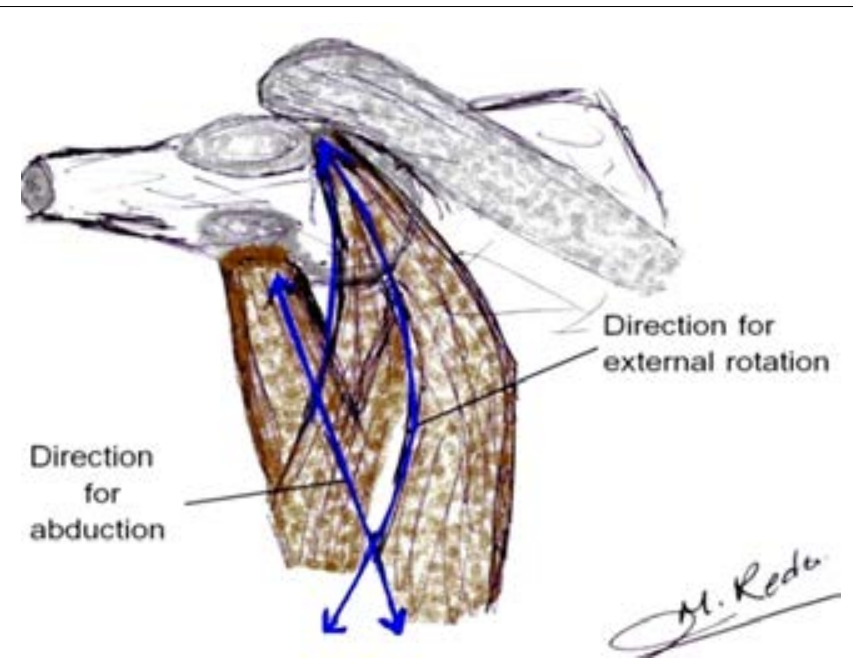

Figure 2a: Diagram for the direction and site of insertion of latissmus dorsi and terries major muscles.

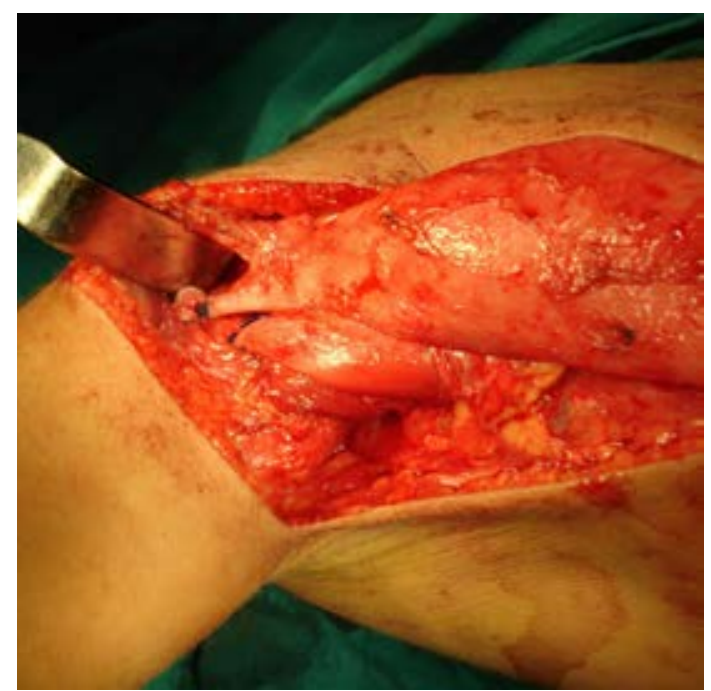

Figure 2b: The direction and site of insertion of latissmus dorsi and terries major muscles.

less than $20^{\circ}$. I used the same concept in this work, especially while assessing the PROM of the shoulder joint at the start of the surgery.

With the same concept, Raimondi et al. [19] were doing the release of subscapularis, and then they waited for the recovery of active external rotators. They preferred to combine both release and transfer in the surgery in children more than 4 year old.

Another concept presented by Muhlig et al. [16] is remarkable. They described a policy for management of internal rotation contracture deformity. They suggested to do muscle release when passive external rotation is less than $30^{\circ}$. And in cases without shoulder joint sublaxation or dislocation, they were doing posterior approach muscle slide operation. In other situation, when there was dislocation or sublaxation of the shoulder, then anterior subscapular tendon lengthening was preferred. They added that, in cases showed no recovery of infraspinatous muscle at the age of 2 years old, then LD muscle transfer was added to the release. I did muscle transfer and release in all cases at the same time, to avoid reoperation with suspected fibrosis and adhesions in the field if the rotator cuff muscles were not regained function after the release surgery. The other reason is to avoid internal rotation contracture recurrence. Also is to provide the cases with rapid, sufficient, and long lasting improvement. Lastly is to limit the costs of 2 surgeries in a country with financial problems.

Hoffer et al. [20] used tmm in the technique to improve active outward rotation of the shoulder. They listed the indications for this when the flexors and abductors of the shoulder are weak against gravity, and when tmm shows cocontraction during active abduction of the shoulder. The third indication is to augement the muscle volume of the cranial part of trapezius muscle transfer.

Bahm and Ocampo-Pavez [21] supposed that the monopolar transfer of the tmm around its vascular pedicle by keeping the insertion of the muscle intact is a perfect transfer to improve shoulder abduction, especially if there is tmm cocontraction during active shoulder abduction.

In group I, I used BDMT by transferring the tendon of tmm to a site proposed to aid in abduction and stabilization of the GH joint. From my opinion my proposed transfer is easier, feasible, and safe for the pedicles of the LD muscle, and tmm muscle. The significant improvement in abduction after BDMT in comparison to SDMT, makes me to say that this technique is a safe, easy, and effective as regard achieving perfect abduction and external rotation function restoration.

Gilbert [11] after his work on 44 cases stated that LD muscle transfer is sufficient for shoulder functions restoration (abduction and external rotation), if the active abduction is more than $90^{\circ}$. In other words, if active external rotation was between $45^{\circ}-90^{\circ}$ the LD muscle transfer was not sufficient. So he advised to add trapezius transfer for shoulder in this situation.

Chen et al. [22] agreed with previous idea, and they added a modification in the transfer. After insertion of the tendon of LD muscle to the insertion of the infraspinatous muscle, they did tenotomy of the tendon of tmm and reattached it to the muscle belly of the LD muscle in its new position to augment its function.

Ahmad et al. [23] asserted that the concomitant transfer of trapezius muscle with LD muscle transfer given marked improvement in both shoulder abduction and external rotation, rather than LD muscle transfer only.

Al-Qattan [24] has a different concept. He argued that there is no differences in the results of LD muscle transfer in correlation with preoperative abduction degrees after his work on 12 cases with deficient shoulder abduction and external rotation.

The derotation osteotomy of the humerus is a traditional method to improve cases with late resistant internal rotation contracture, But this procedure doesn't care about the GH joint dysplasia or shoulder joint dynamics, rather than its high failure rate $[25,26]$.

Another surgical idea by opening the GH joint anterior capsule, then tilting the humeral head laterally within the deformed glenoid cavity was done by some surgeons. But this surgical technique carries the risk of severe external rotation contracture, which is might be disabling more than internal rotation contracture itself $[3,27,28]$.

Finally, Bidirectional double muscle transfer procedure had significant higher degree of improvement in shoulder abduction and external rotation than single muscle transfer procedure. The young age gives better results. Therefore, this technique is recommended as an optimal procedure to improve both abduction and external rotation of shoulder joint. 
Citation: Ahmad M (2015) Bidirectional Double Muscle Transfer to Restore Shoulder Abduction and External Rotation in Late Obstetric Brachial Plexus Injuries. Surgery Curr Res 5: 216. doi:10.4172/2161-1076.1000216

Page 5 of 5

\begin{tabular}{|c|c|c|c|c|}
\hline \multirow{2}{*}{$\begin{array}{c}\text { Shoulder } \\
\text { Abduction }\end{array}$} & \multicolumn{2}{|c|}{ Group 1: BDMT (n=17) } & \multicolumn{2}{c|}{ Group 2: SDMT (n= 23) } \\
\cline { 2 - 5 } & before & After & before & After \\
\hline range & $30-75$ & $95-160$ & $40-90$ & $90-130$ \\
\hline Mean & 51.76 & 129.12 & 60.22 & 108.69 \\
\hline SD & 11.45 & 20.33 & 12.83 & 11.10 \\
\hline \% of change & \multicolumn{2}{|c|}{0.000} \\
\hline P value of tt & \multicolumn{2}{|c|}{$0.000 .48 \%$} \\
\hline P value VS BDMT & \multicolumn{2}{|c|}{0.000} \\
\hline r (with age) & & $-.572^{*}$ & & $-.575^{* *}$ \\
P value & & 0.016 & & 0.004 \\
\hline
\end{tabular}

Table 2: A comparison between shoulder abduction improvements in the two procedures.

\begin{tabular}{|c|c|c|c|c|}
\hline \multirow{2}{*}{$\begin{array}{c}\text { Shoulder External } \\
\text { rotation }\end{array}$} & \multicolumn{2}{|c|}{ Group 1: BDMT $(n=17)$} & \multicolumn{2}{|c|}{ Group 2: SDMT $(n=23)$} \\
\hline & before & After & before & After \\
\hline range & $0-20$ & $65-90$ & $0-30$ & $60-90$ \\
\hline Mean & 5.88 & 81.47 & 6.09 & 72.83 \\
\hline SD & 8.70 & 8.43 & 9.88 & 10.75 \\
\hline$\%$ of change & & 1285.54 & & 1095.89 \\
\hline$P$ value of $t t$ & \multicolumn{2}{|c|}{0.000} & \multicolumn{2}{|c|}{0.000} \\
\hline$P$ value VS BDMT & & & & 0.009 \\
\hline $\begin{array}{l}r \text { (with age) } \\
\text { P value }\end{array}$ & & $\begin{array}{l}-.720 \text { ** } \\
0.001\end{array}$ & & $\begin{array}{c}-.578^{* *} \\
0.004\end{array}$ \\
\hline
\end{tabular}

Table 3: A comparison between shoulder external rotation improvements in the two procedures.

\begin{tabular}{|c|c|c|c|c|}
\hline \multirow{2}{*}{$\begin{array}{l}\text { Shoulder } \\
\text { flexion }\end{array}$} & \multicolumn{2}{|c|}{ Group 1: BDMT $(n=17)$} & \multicolumn{2}{|c|}{ Group 2: SDMT $(n=23)$} \\
\hline & before & After & before & After \\
\hline Range & $0-30$ & $50-90$ & $10-25$ & $60-90$ \\
\hline Mean & 10.59 & 74.41 & 11.96 & 68.26 \\
\hline SD & 7.48 & 11.16 & 5.38 & 8.99 \\
\hline$\%$ of change & & $602.64 \%$ & & $470.73 \%$ \\
\hline$P$ value of $t t$ & \multicolumn{2}{|c|}{0.000} & \multicolumn{2}{|c|}{0.000} \\
\hline P VS BDMT & & & & 0.061 (NS) \\
\hline $\begin{array}{l}r \text { (with age) } \\
P \text { value }\end{array}$ & & $\begin{array}{l}-.523^{*} \\
0.031\end{array}$ & & $\begin{array}{l}-.448^{*} \\
0.032\end{array}$ \\
\hline
\end{tabular}

Table 4: A comparison between shoulder flexion improvements in the two procedures.

\section{References}

1. Pollack RN, Buchman AS, Yaffe H, Divon MY (2000) Obstetrical brachial palsy: pathogenesis, risk factors, and prevention. Clin Obstet Gynecol 43: 236-246.

2. Hoeksma AF, Ter Steeg AM, Dijkstra P, Nelissen RG, Beelen A, et.al. (2003) Shoulder contracture and osseous deformity in obstetrical brachial plexus injuries. J Bone Joint Surg 85: 316-322.

3. Nath RK (2007) Obstetric brachial plexus injuries-Erb's palsy. (1 $1^{\text {st }}$ edn.) Nath method of diagnosis and treatment. Virtual Bookworm.com Publishing, College Station: 79.

4. Garcia-Castellano JM, Diaz-Herrera P, Morcuende JA (2000) Is bone a targettissue for the nervous system? New advances on the understanding of their interactions. lowa Orthop J 20: 49-58.

5. Terzis JK, Kokkalis ZT (2010) Bone discrepancy as a powerful indicator for early surgery in obstetric brachial plexus palsy. Hand (NY) 5: 386-396

6. Birch R, Bonney G, Wynn Parry CB (1998) Birth lesions of the brachial plexus. (Birch R, Bonney G, Wynn Parry CB edn.) Surgical disorders of the peripheral nerves, Churchill Livingstone, New York: 209-233.

7. Chuang DC, Ma HS, Wei FCA (1998) new strategy of muscle transposition for treatment of shoulder deformity caused by obstetric brachial plexus palsy. Plast Reconstr Surg 101: 686-694.

8. Waters PM, Allan E, Peljovich E (1999) Shoulder reconstruction in patients with chronic brachial plexus birth palsy. Clin Orthop 364: 144-152.

9. Birch R (2001) Medial rotation contracture, posterior dislocation of the shoulder ( Gilbert A edn.) Brachial plexus injuries. Hampshire (UK), Taylor \& Francis 249-259.
10. Al-Qattan MM (2003) Classification of secondary shoulder deformities in obstetric brachial plexus palsy. J Hand Surg [Br] 28: 483-486.

11. Gilbert A (1993) Obstetrical brachial plexus palsy. (Tubiana R edn.) The Hand. Philadelphia, WB Saunders. 4: 575-601.

12. Ahmad MR (2011) Operations around shoulder. (Ahmad MR. edn.) Management of late obstetric brachial plexus. IAP Lambert academic publishing, Beau Bassin, Mauritius: 80-81.

13. Nath RK, Humphries AD (2009) Computed tomography of the shoulders in patients with obstetric brachial plexus injuries: a retrospective study. Ann Surg Innov Res 2: 4-9.

14. Nath RK, Amrani A, Melcher SE, Eichhorn MG (2009) Triangle tilt surgery in an older pediatric patient with obstetric brachial plexus injury. ePlasty 9: e26.

15. 15- Abdelgawad A, Naga O (2014) Birth injuries and orthopedic manifestations in newborns. ( $1^{\text {st }}$ edn.) Pediatric Orthopedics: Handbook for primary care physicians. Springer New York: 75-83.

16. Muhling RS, Blaauw G, Slooff ACJ, Kortleve JW, Tonino AJ (2001) Conservative treatment of obsterical brachial plexus palsy and rehabilitation. (Gilbert A. edn.) Brachial plexus injuries. London, Martin Dunitz Ltd: 173-187.

17. Covey DC, Riordian DC, Milstead ME, Albright JA (1992) Modification of the L'Episcopo procedure for brachial plexus birth palsies. J Bone Joint Surg $[\mathrm{Br}]$ 74: 897-901.

18. Gilbert A, Brockman R, Carlioz H (1991) Surgical treatment of brachial plexus birth palsy. Clin Orthop. 264: 39-47.

19. Raimondi PL, Muse A, Saporiti E (2001) Palliative surgery: shoulder paralysis. (Gilbert A edn.) Brachial plexus injuries. London, Martin Dunitz Ltd: 225-238.

20. Hoffer M, Wickenden R, Roper B (1978) Brachial plexus birth palsies. Results of tendon transfers to the rotator cuff. J Bone Joint Surg 60: 691-695.

21. Bahm J and Ocampo-Pavez C (2009) Monopolar teres major muscle transposition to improve shoulder abduction and flexion in children with sequelae of obstetric brachial plexus palsy. J Brachial Plexus and Peripheral Nerve Injury 4: 20.

22. Chen L, Gu Y, Hu S (2002) Applying transfer of trapezius and/or latissimus dorsi with teres major for recontruction of abduction and external rotation of the shoulder in obstetrical brachial plexus palsy. J Recons Microsurg 18: 275-280.

23. Ahmad MR, El-Sadek AN, Abdeldaym A (2011) Compined latissimus dorsi and trapezius transfer to improve zero shoulder after brachial plexus palsy. Egypt $\mathrm{J}$ plastic reconstr Surg 35: 83-92.

24. Al-Qattan MM (2003) Latissimus dorsi transfer for external rotation weakness of the shoulder in obstetric brachial plexus palsy. J Hand Surg [Br] 28: 487-490.

25. Al-Qattan MM (2002) Rotation osteotomy of the humerus for Erb's palsy in children with humeral head deformity. J Hand Surg Am 27: 479-483.

26. Waters PM, Bae DS (2006) The effect of derotational humeral osteotomy on global shoulder function in brachial plexus birth palsy. J Bone Joint Surg Am 88: 1035-1042.

27. Abzug JM, Chafetz RS, Gaughan JP, Ashworth S, Kozin SH (2010) Shoulder function after medial approach and derotational humeral osteotomy in patients with brachial plexus birth palsy. J Pediatr Orthop 30: 469-474.

28. Abdelgawad A, Pirela-Cruz MA (2014) Humeral Rotational Osteotomy for Shoulder Deformity in Obstetric Brachial Plexus Palsy: Which Direction Should I Rotate? .The Open Orthopaedics J 8: 130-134. 